HERRAMIENTAS PARA EL APRENDIZAJE COLABORATIVO EN RED: EL CASO DE LA UNIVERSITAT OBERTA DE CATALUNYA (UOC).

Resumen: El estudio se centra en el aprendizaje colaborativo en red. A partir de un diseño cualitativo de investigación, tiene por objetivo analizar los usos que realizan los estudiantes de la UOC de las diferentes herramientas para el trabajo en grupo. Este objetivo se aborda a partir de dos elementos clave de los procesos colaborativos virtuales: el aprendizaje y los aspectos sociales de la comunicación. Partiendo del caso concreto de una asignatura, se analiza una prueba piloto en la que se introdujo el wiki para el trabajo grupal. Los resultados evidencian que el debate y el Chat se utilizaron mayormente para la comunicación; el wiki para la construcción del trabajo; y el área de ficheros como repositorio compartido de información digital.

Palabras clave: Aprendizaje colaborativo, herramientas colaborativas, wikis, debate, Chat, aspectos sociales.

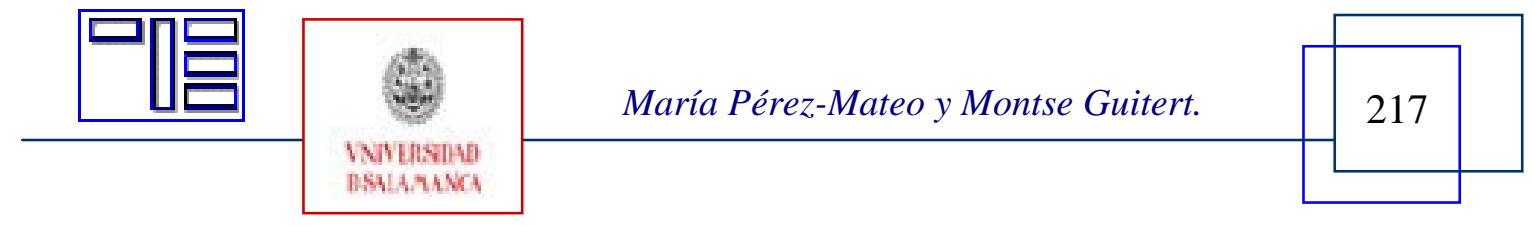




\section{ONLINE COLLABORATIVE LEARNING TOOLS: THE CASE OF THE UNI- VERSITAT OBERTA DE CATALUNYA (UOC).}

Abstract: This study focuses on online collaborative learning. From a qualitative research design, the objective of this study is to analyze the uses that UOC students make of the different tools available for group work. This goal is approached through two main elements of online collaborative processes: learning and social aspects of communication. Starting from a specific subject case, the study analyzes a pilot test where wiki was introduced for collaborative work. Results showed that Debate and Chat were used mainly for communicating; wiki for building up the virtual Project; and the file area as a shared repository of digital information.

Key words: Collaborative learning, collaborative tools, wikis, debate, chat, social aspects.

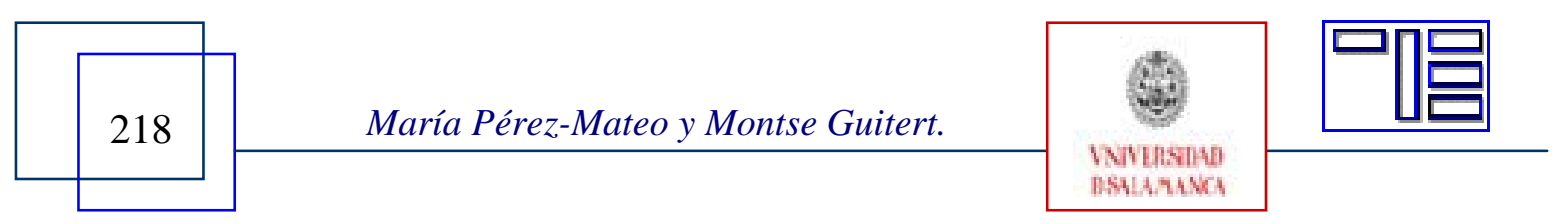




\section{OUTILS D'APPRENTISSAGE COLLABORATIF EN RÉSEAU: LE CAS DE L'UNIVERSITAT OBERTA DE CATALUNYA (UOC).}

Sommaire: L'étude se concentre sur l'apprentissage collaboratif en réseau. Du point de vue de la recherche qualitative, elle a pour objectif d'analyser les utilisations faites par des étudiants de l'UOC des différents outils pour le travail d'équipe. Cet objectif est abordée à partir de deux éléments clés des processus de collaboration virtuelle: l'apprentissage et les aspects sociaux de la communication. On démare sur le cas concrèt d'une matière et on analyse un essai pilote dans lequel on a introuidt le wiki pour le travail de groupe. Les résultats montrent que le débat et le chat on été utilisés pincipalement pour la communication, le wiki pour l'elaboration des travaux et les fichiers comme espace partagé de l'information numérique.

Mots-clefs: apprentissage collaboratif, outils de collaboration, les wikis, discussion, chat, les aspects sociaux.

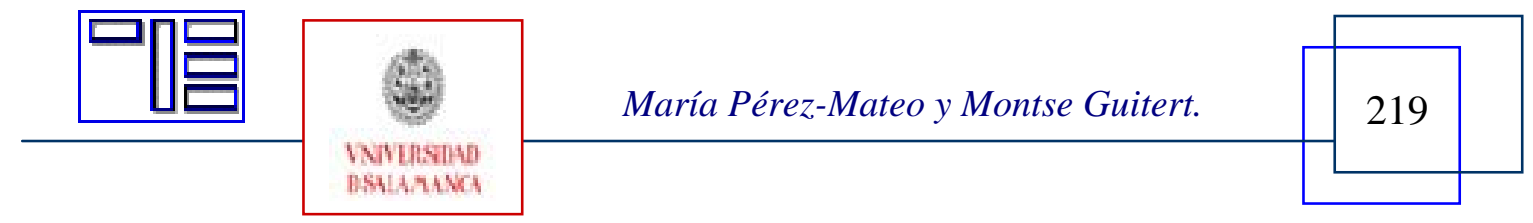




\title{
HERRAMIENTAS PARA EL APRENDIZAJE COLABORATIVO EN RED: EL CASO DE LA UNIVERSITAT OBERTA DE CATALUNYA (UOC).
}

\author{
María Pérez-Mateo Subirà \\ mperez-mateo@uoc.edu \\ Internet Interdisciplinary Institute (IN3) \\ Universitat Oberta de Catalunya \\ Montse Guitert Catasús \\ mguitert@uoc.edu \\ Universitat Oberta de Catalunya
}

\section{1.- INTRODUCCIÓN.}

Esta investigación aborda los grupos colaborativos virtuales que tienen lugar en la asignatura Multimedia y Comunicación de la Universitat Oberta de Catalunya (UOC). El objetivo principal del estudio es analizar cómo los estudiantes de la UOC utilizan las diferentes herramientas disponibles (debate, wiki,...) para desarrollar un proyecto virtual en grupos reducidos (3-4 miembros). Este objetivo se abordará a partir de dos elementos fundamentales de los procesos de colaboración virtual: el aprendizaje y los elementos sociales de la comunicación.

Partiendo del caso concreto de la asignatura de Multimedia y Comunicación para los estudiantes de Ingeniería Informática de la UOC, se analiza una prueba piloto en la que se introdujo el wiki para el trabajo en grupo virtual.

El artículo se organiza en cuatro apartados generales. En primer lugar, se presenta una aproximación conceptual al objeto de estudio a partir de una revisión bibliográfica. A continuación, se detalla la metodología y procedimiento seguidos para la obtención de los datos, así como una breve descripción de la asignatura Multimedia y Comunicación. Seguidamente, se presentan los apartados de análisis y discusión de resultados. Finalmente, se exponen las conclusiones.

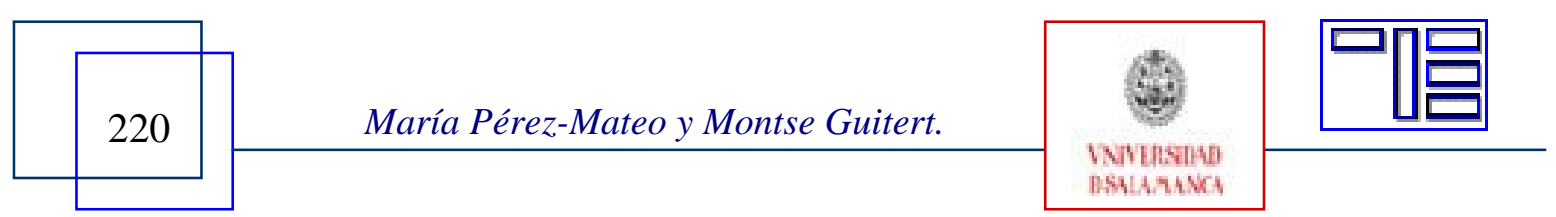




\section{2.- APROXIMACIÓN CONCEPTUAL.}

En el contexto del Espacio Europeo de Educación Superior (EEES), el trabajo en equipo adquiere una importancia fundamental entre las competencias genéricas que los estudiantes deben adquirir.

Siguiendo a Dillenbourg (1999), entendemos que un proceso de aprendizaje puede considerarse colaborativo cuando un grupo de estudiantes se dedican de forma coordinada, durante un tiempo suficiente, a resolver juntos un problema o realizar una actividad. Es un "proceso en el que cada individuo aprende más de lo que aprendería por sí solo, fruto de la interacción de los integrantes del equipo” (Guitert y Giménez, 2000: 114), a partir del trabajo conjunto y el establecimiento de metas comunes.

El concepto de colaboración incluye dos elementos intrínsecos: uno enfocado a los procesos cognitivos y otro a los elementos comunicativos, abarcando los aspectos más sociales de esta comunicación. Aunque, tradicionalmente, el objetivo de los grupos en el ámbito educativo se ha orientado al desarrollo de capacidades cognitivas, no significa que los aspectos sociales de la interacción generada no existan o no tengan un papel relevante. Si bien muchas investigaciones los han infravalorado, excluido o analizado separadamente del aprendizaje cognitivo (Contreras-Castillo, Favela, Pérez y Santamaría, 2004), cada vez son más los estudios que analizan el papel fundamental que desempeñan los aspectos sociales, informales o afectivos del aprendizaje en el desarrollo de proyectos colaborativos con éxito.

El entorno virtual inaugura oportunidades innovadoras para la colaboración, la comunicación y la producción de conocimientos y aumenta las posibilidades para poder aprender y trabajar en equipo a las cuales se veía limitada hasta ahora la cooperación en un entorno de trabajo presencial (Harasim, Hiltz, Turoff y Teles, 2000). Si bien han surgido diversas plataformas con licencia de pago para la colaboración en red, como por ejemplo la comunidades de CSCL (Computer-Supported Collaborative Learning) y CSCW (Computer Support for Cooperative Work), la actual web 2.0 fomenta la implementación de plataformas de uso libre (Moodle, etc.) así como otras herramientas específicas (wikis, blogs, etc.).

Sin embargo, la literatura que aborda las herramientas de la web2.0 para el aprendizaje colaborativo evidencia que la mayor parte de los estudios se centran más en las herramientas que en los procesos educativos y sociales que tienen lugar como consecuencia de su uso. En este contexto, la investigación que se presenta analiza una prueba piloto en la que se utiliza el wiki además de las herramientas habituales (debate y área de ficheros) para la realización de un proyecto virtual colaborativo en grupos reducidos de 4 a 5 personas.

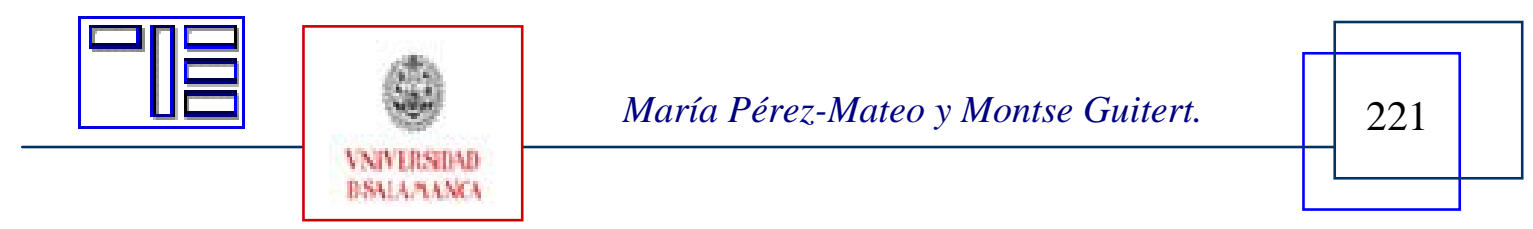


Revista Electrónica Teoría de la Educación.

Educación y Cultura en la Sociedad de la Información.

http://www.usal.es/teoriaeducacion

Vol. 10. No 1. Marzo 2009

\section{3.- MARCO METODOLÓGICO.}

La investigación presenta un enfoque cualitativo a partir del estudio de casos (Merriam, 1998). Con el objetivo de analizar el uso de las herramientas disponibles y la implicación en los aspectos de aprendizaje y sociales de los grupos colaborativos de la UOC, se plantea una pregunta principal que guía la investigación:

¿Cómo utilizan las diferentes herramientas disponibles los estudiantes de la UOC para favorecer los procesos de aprendizaje colaborativo?

\subsection{Escenario de investigación.}

La UOC [1] se creó específicamente para facilitar el acceso a la educación superior mediante el uso e implementación de las Tecnologías de la Información y la Comunicación (TIC) y ofrece un modelo de formación basado y desarrollado íntegramente en Internet a partir del Campus Virtual. Teniendo en cuenta la importancia que adquiere el trabajo en grupo en términos del EEES, en la UOC algunas asignaturas desarrollan o incorporan a sus planteamientos pedagógicos estrategias de aprendizaje colaborativo. Una de estas asignaturas, trasversal a todos los estudios de la UOC, ha sido el escenario de esta investigación: Multimedia y Comunicación (MyC). El escenario concreto que se presenta responde a una prueba piloto en que se introduce el wiki para el trabajo en grupo de manera voluntaria. Los materiales de la asignatura no hacían referencia a estas herramientas, aunque el consultor ofreció orientaciones mediante el tablón general de la asignatura.

Con la finalidad de llevar a cabo el trabajo de campo, se escogió un aula de Ingeniería Informática. Teniendo en cuenta el objetivo general de esta investigación, se consideró que este perfil de estudiante contaba con las características idóneas, presuponiéndole una facilitad en el uso de las herramientas que permitiese observar las consecuentes diferencias en las dinámicas a partir de la combinación de éstas. Si bien MyC para Ingeniería Informática contaba con 5 aulas, se escogió una de ellas atendiendo a la accesibilidad del profesor. El aula concreta en la que se desarrolló el estudio contaba con 68 estudiantes, distribuidos en 14 grupos con una media de 3 a 5 estudiantes cada uno. En la elección de los grupos concretos de análisis debían darse las siguientes características:

1. Utilizar diferentes herramientas para alcanzar el mismo objetivo: realizar el proyecto virtual colaborativamente.

2. Llevar a cabo el proyecto en el espacio del Campus Virtual de la UOC de manera íntegra.

3. Desarrollar una dinámica que les condujese a obtener un buen resultado, tanto durante el transcurso de la asignatura como al final de la misma. El hecho de ob-

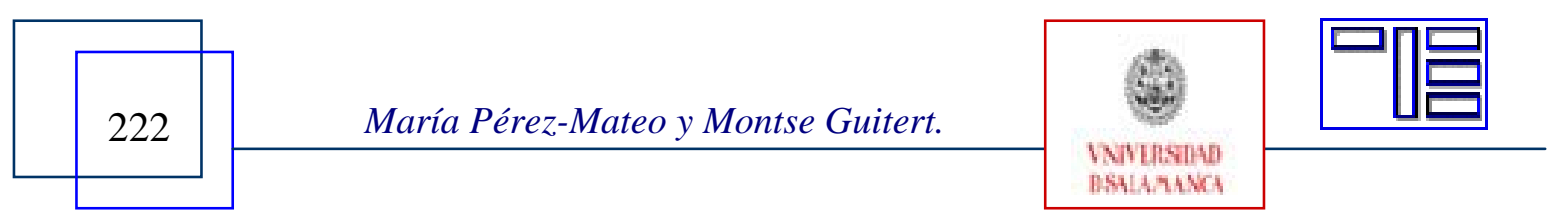




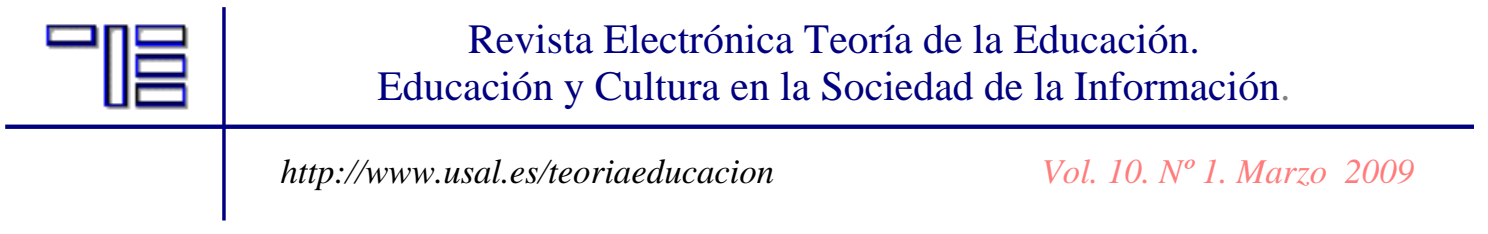

tener un buen resultado habría de garantizar en uso adecuado de las diferentes herramientas.

4. Desarrollar dinámicas suficientemente diferentes como para poder observar las divergencias en el uso de las herramientas y sus implicaciones en el desarrollo del proyecto.

Atendiendo a estos requisitos, entre los 14 grupos, se escogieron 3 que presentaban diversas similitudes y diferencias.

Por una parte, los tres obtuvieron la máxima nota en la dinámica grupal y se mantuvo el mismo número de miembros durante el proceso. Entre las herramientas que facilitaba la asignatura, las escogidas por estos grupos fueron básicamente medios asíncronos: debate, wiki y área de ficheros, las cuales fueron combinadas para la consecución del trabajo. Toda la interacción que llevaron a cabo los integrantes de los grupos quedó registrada en sus respectivos espacios virtuales.

Por otra parte, estos tres equipos presentaban diferentes características en referencia a la dinámica, uso de las herramientas y recursos sociales:

\begin{tabular}{cccccc}
\hline GRUPO & $\begin{array}{c}\mathbf{N}^{0} \\
\text { PERS. }\end{array}$ & $\begin{array}{c}\mathbf{N}^{0} \text { MENS. } \\
\text { DEBATE }\end{array}$ & $\begin{array}{c}\text { Mg ÀREA } \\
\text { FICHEROS }\end{array}$ & $\begin{array}{c}\text { USO } \\
\text { WIKI }\end{array}$ & USO CHAT \\
\hline Admin2.0 & 4 & 480 & 60 & Bajo & No \\
\hline Edu2.0 & 5 & 209 & 7.5 & Medio & No \\
\hline HeRoSaPrI & 4 & 179 & 93 & Intenso & Sí \\
\hline
\end{tabular}

Tabla. 1. Características de los grupos analizados.

\subsubsection{Multimedia y Comunicación.}

MyC tiene como finalidad principal poner en práctica estrategias de aprendizaje en un entorno virtual, a partir de la adquisición de habilidades expresadas en términos de competencias genéricas en TIC en un escenario de trabajo cooperativo que trasciende más allá de la tarea individual (Guitert et al., 2007).

El planteamiento pedagógico de MyC se desarrolla en varias etapas, esquematizadas en la Figura 1 para la creación de un proyecto virtual mediante diferentes actividades colaborativas y de manera asíncrona. Ésta permite observar cómo se desarrolla un proyecto virtual paso a paso, en el que la planificación - replanificación del trabajo, la actividad individual y de grupo y el feedback del estudiante y el profesor adquieren un papel clave. Al comenzar el trabajo en grupo, se proporciona a los estudiantes un documento que ofrece orientaciones y les ayuda antes de iniciar el proceso grupal, haciendo hincapié en las actitudes que facilitan el trabajo en quipo en un entorno virtual y las diferentes fases por las que pasa la vida de un grupo en un entorno virtual de aprendizaje. Respecto al

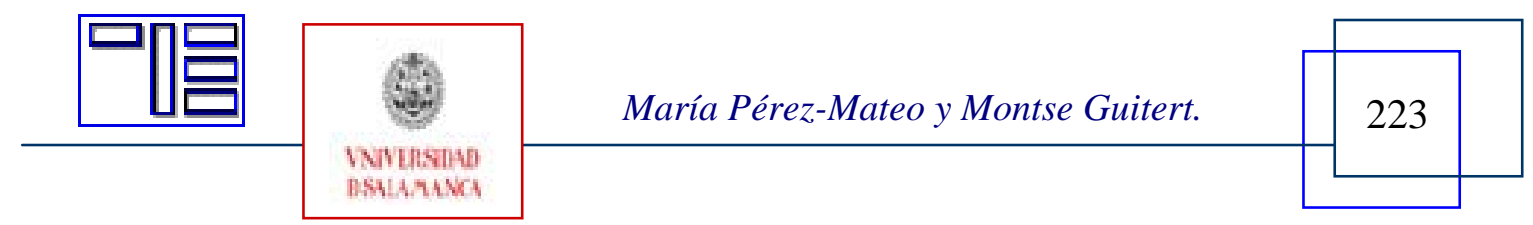


Revista Electrónica Teoría de la Educación.

Educación y Cultura en la Sociedad de la Información.

http://www.usal.es/teoriaeducacion

Vol. 10. No 1. Marzo 2009

sistema de evaluación, el trabajo en grupo es una competencia que se evalúa de manera individual y en grupo.

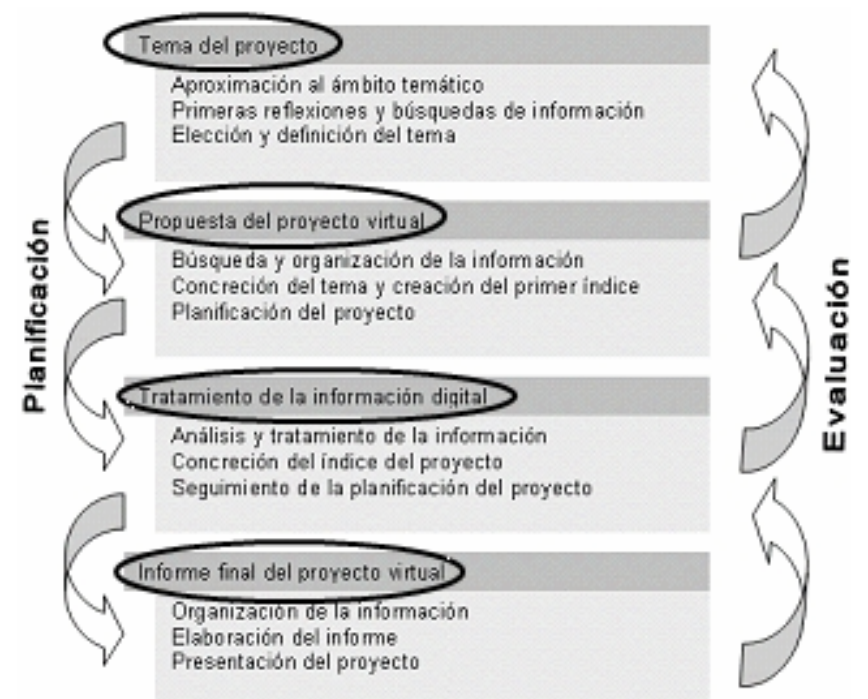

Figura 1. F́ases del proyecto virtual

\subsection{Instrumentos de recogida y análisis de datos.}

Atendiendo al carácter cualitativo del que parte la investigación, el proceso de recogida de datos se basó en 2 instrumentos fundamentales: la observación y dos preguntas de un cuestionario.

\subsubsection{Observación.}

La observación de los grupos se realizó en los espacios virtuales que la asignatura facilita a cada grupo:

5. Tablón del grupo. Espacio donde el consultor hace sugerencias a los estudiantes y donde envía las valoraciones de las diferentes PECs.

6. Debate. Presenta una estructura similar a los foros virtuales y constituye el principal espacio donde se lleva a cabo la interacción entre los miembros de los grupos.

7. Chat. Herramienta de comunicación síncrona que solamente incluye a los miembros del grupo.

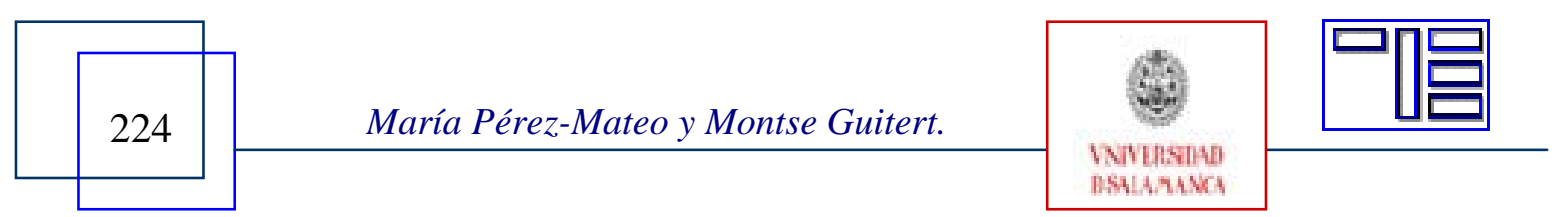




\begin{tabular}{|c|c|c|}
\hline ص司 & $\begin{array}{l}\text { Revista Electrónic } \\
\text { Educación y Cultura en }\end{array}$ & $\begin{array}{l}\text { ducación. } \\
\text { la Información. }\end{array}$ \\
\hline & http://www.usal.es/teoriaeducacion & Vol. 10. No 1. Marzo 2009 \\
\hline
\end{tabular}

8. Área de archivos. Espacio destinado al almacenamiento de los diferentes archivos y documentos que crea el grupo en las diferentes fases del proyecto.

9. Wiki. Espacio web colaborativo que puede ser editado por varios usuarios. Permite todas las acciones comunes de este tipo de espacios (crear, modificar y borrar el contenido de una página) y que pueden ser consultados mediante un historial de acciones.

\begin{tabular}{|lll}
\hline Grup 2 _Educaweb & Enviar un mensaje al responsable \\
\hline Tablón $(0 / 4)$ & Xet \\
Debate $(0,175)$ & Áreas de archivas & \\
\hline
\end{tabular}

Fig. 2. Herramientas de los grupos colaborativos de la UOC.

\subsubsection{Cuestionario.}

El cuestionario tuvo carácter voluntario, anónimo y no evaluable. En general, abordaba tanto los procesos generales del trabajo en grupo como los relativos a la dimensión social, sentimiento de grupo, satisfacción del estudiante, herramientas, procesos de aprendizaje y papel del consultor. Si bien el cuestionario contaba con 7 secciones, para esta investigación únicamente se tuvo en cuenta una de ellas: la vinculada a las herramientas. Ésta constaba de dos preguntas, una cerrada y una abierta. La primera recogía las herramientas concretas que había utilizado cada grupo mientras que la segunda requería una valoración de éstas para el desarrollo del proyecto.

Con el objetivo de recoger la mayor cantidad de datos que permitiesen evidenciar los resultados más allá de los casos seleccionados, el cuestionario fue enviado a las cinco aulas de la asignatura MyC de Ingeniería Informática. Sin embargo, se requería explicitar el nombre del grupo en el cual se había trabajado. Este hecho permitió contrastar la observación con los datos recogidos en el cuestionario de los tres grupos escogidos así como contrastarlos con los otros equipos de las diferentes aulas. El cuestionario fue contestado por 44 personas a través de la herramienta Netquest, que se desarrolla íntegramente de manera virtual.

\subsection{Procedimiento de análisis.}

El procedimiento de análisis de los datos se basó principalmente en la observación de los espacios de los tres grupos escogidos. Dicha observación se sistematizó mediante el uso de unas categorías que coincidían con las secciones del cuestionario citadas anteriormente.

A partir de aquí y a medida que se profundizaba en aspectos concretos de relevancia para la investigación, se procedía a la triangulación de los datos obtenidos de manera

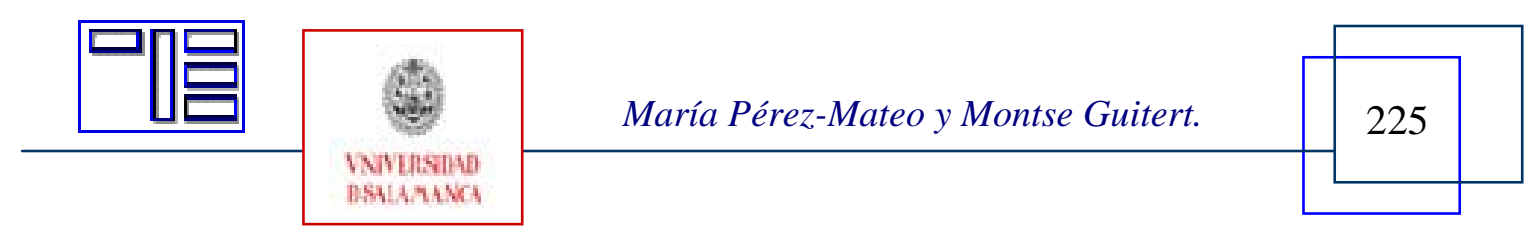


cualitativa por las investigadoras a través de la observación con los de la sección referente a las herramientas del cuestionario.

Cabe remarcar que los procesos de recogida y análisis de datos se realizaron teniendo en cuenta los aspectos éticos que guían la investigación en las Ciencias Sociales, tanto en lo referente a los aspectos personales como a los datos recogidos.

\section{4.- ANÁLISIS DE DATOS.}

La observación de los espacios de los grupos y el análisis del cuestionario revelan que los tres equipos escogidos presentaron dinámicas diferentes en función de las herramientas elegidas, las maneras de combinarlas y el uso que realizaron de éstas. En este apartado, se realiza un análisis descriptivo de estas dinámicas.

\subsection{Admin2.0.}

Admin2.0 focalizó su dinámica en el debate, como demuestra el elevado número de mensajes enviados a este espacio: 480. Utilizaron esta herramienta como medio para la comunicación y la interacción, depositando los diferentes archivos que iban creando en el área de ficheros. Esta manera de proceder fue acordada desde el principio. En esta línea, uno de ellos decía en el cuestionario: "planteamos que todos los documentos e información encontrada, así como las distintas etapas del trabajo, se fuesen subiendo al área de ficheros para que estuviesen a disposición de todo el grupo”.

El grupo Admin2.0 organizó el área de ficheros por carpetas en función de los siguientes acuerdos iniciales:

"La estructura de dicha área es la siguiente:

- Directorio PACS: se guardarán las diferentes versiones de los documentos de las PAC's sobre los que se irán trabajando.

- Directorio Planificación: se guardarán los documentos relativos a acuerdos alcanzados, reuniones, planificación del grupo, etc.

- Directorio Plantilla: se guardarán los diferentes documentos de plantillas a utilizar por los miembros de Admin2.0 (...).

- Directorio Recursos: documentos de ámbito general (...)”.

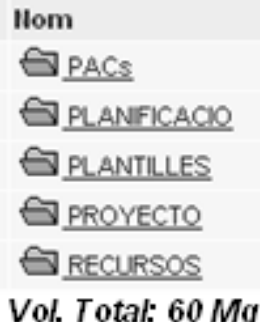

Vol. Total: $60 \mathrm{Mg}$

Fig. 3.Carpetas Admin2.0

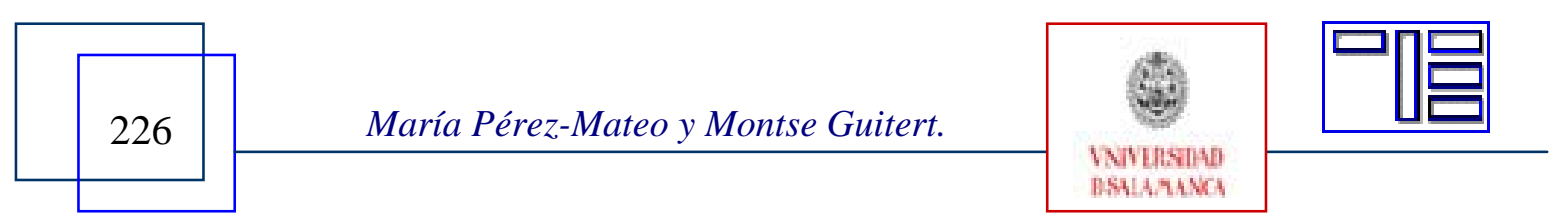


Posteriormente y como consecuencia de la dinámica desarrollada, añadieron la carpeta "Proyecto".

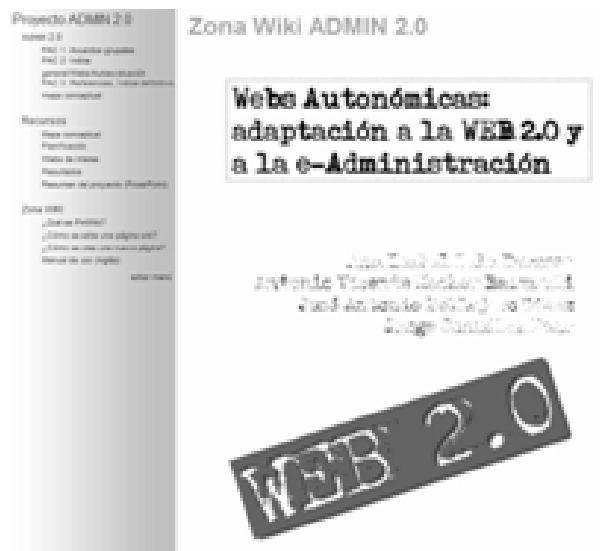

Fig. 4. Carpeta de Proyecto.

En la medida que finalizaban los diferentes archivos correspondientes a las PECs subían el resultado al espacio de wiki, utilizándolo para la presentación de los diferentes archivos generados a partir del proceso en grupo. De esta manera, el wiki se destinó exclusivamente a la publicación del trabajo en formato web, deviniendo una presentación virtual del trabajo realizado que personalizaron con una imagen relacionada con el tema. El uso del wiki como herramienta de publicación tuvo como consecuencia un elevado número de mensajes en el debate y el uso intensivo del área de ficheros.

\subsection{Edu2.0.}

El debate fue donde el grupo llevó a cabo la mayor parte de la comunicación (209 mensajes), siendo "imprescindible" para desarrollar el proyecto y tomándolo "como punto de partida para la comunicación asíncrona". La dinámica en este espacio fue consensuada en los acuerdos iniciales y consistía en que "normalmente un miembro del grupo empieza un tema o línea de actuación y los otros miembros se añaden enriqueciendo y/o dando objetividad”. Sin embargo y como habían acordado en la planificación inicial, el grupo Edu2.0 utilizó el wiki "como herramienta de apoyo a nuestro trabajo", deviniendo el espacio donde "hemos trabajado con la información propiamente del proyecto”. Los acuerdos iniciales también recogían el procedimiento respecto a la manera en que se complementarían estos espacios: "es en el debate donde nos comunicamos para informar de las modificaciones que se han hecho en el wiki o en el área de ficheros". Efectivamente, los siguientes comentarios del debate muestran el equilibrio entre los dos espacios:

"Necesitaría ayuda para hacer el índice del proyecto. En el wiki no hay mucha información”.

"En el wiki he abierto una página para hacer nuestras reflexiones sobre el grupo. Sería bueno que cada uno de nosotros diga lo suyo”.

"El título del proyecto parece que todavía no nos ha quedado claro. ¿Qué os parece participar en una "lluvia de ideas" o "preguntas periodísticas" en la wiki? Cada uno que proponga el título o títulos que le parezcan y pasado un cierto periodo de tiempo prudencial sacaremos la conclusión”.

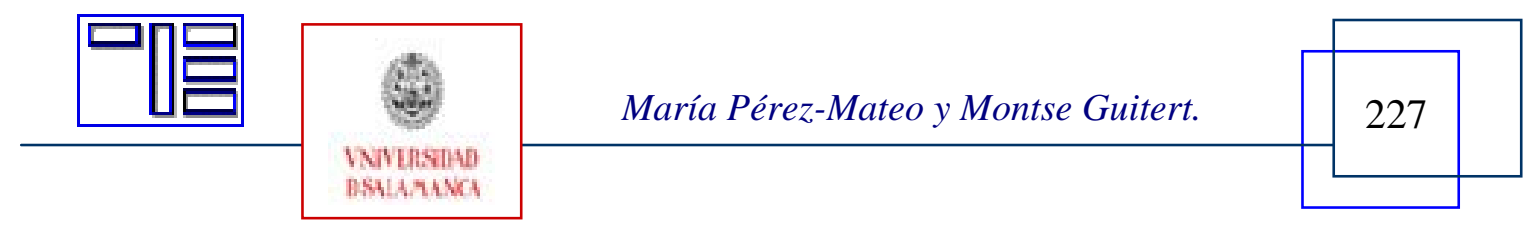


Los dos últimos comentarios evidencian cómo el wiki resultó una herramienta "para llegar a acuerdos (con lluvia de ideas por ejemplo)”. Un ejemplo de esta discusión en el espacio wiki es el siguiente comentario "Yo esto no lo pondría en este apartado, lo pondría en el análisis de los grupos-clase en nuestra práctica”. Aún así, no encontramos muchos elementos de discusión y comunicación, propios de los procesos de construcción de conocimiento. Para Edu2.0 el wiki sirvió para crear y modificar los diferentes documentos, no conteniendo el archivo final que era construido a partir de las versiones del wiki y almacenado en el área de ficheros.

El aspecto de la portada principal del wiki evidencia que fue considerado como una herramienta de trabajo más que una publicación web del trabajo. De esta manera, Edu2.0 utilizó el área de ficheros exclusivamente para guardar los documentos definitivos, construyendo las diferentes versiones en el wiki y debate y discutiendo a través del debate y en algunas ocasiones en el wiki. Por tanto, guardaron muy pocos archivos en este espacio y normalmente por triplicado, teniendo en cuenta que de cada documento guardaban tres versiones diferentes: el *.pdf; *.zip y; *.odt. Edu2.0 organizó este espacio en función de las PECs y el trabajo que iban desarrollando que se relacionaba con las Web Quest (WQ). Sin embargo, este aspecto organizativo no quedó contemplado en sus acuerdos iniciales, sino que fue configurado durante el proceso.

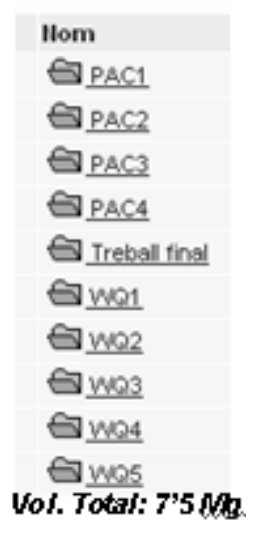

Fig.5. Edu2.0

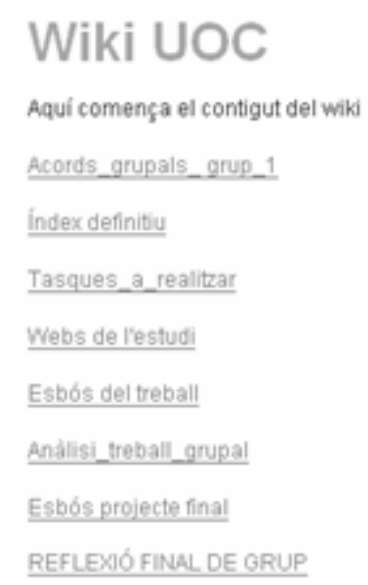

Fig. 6. Wiki UOC

A diferencia de Admin2.0, Edu2.0 realizó menos mensajes en el debate porque utilizó también el wiki como herramienta para la construcción del proyecto final. Este grupo se basó fundamentalmente en estas dos herramientas, almacenando en el área de ficheros las versiones finales de los diferentes documentos que creaban. El mayor uso de los diferentes espacios en contraposición al área de ficheros se evidencia en el volumen total de esta área (7’5 Mg).

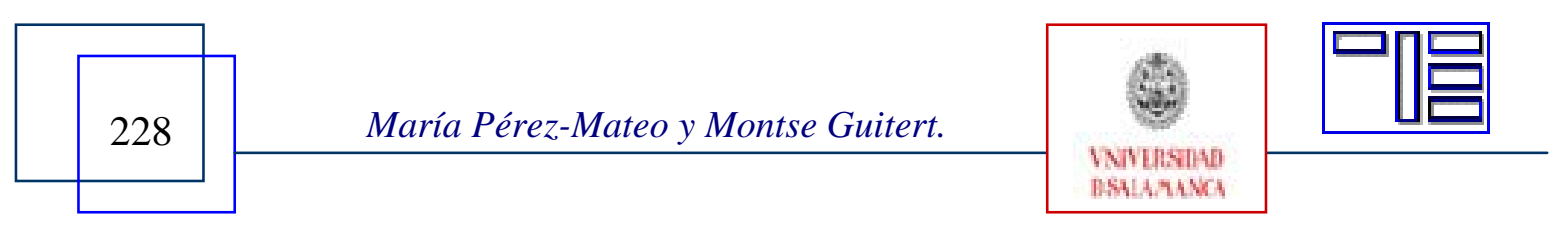




\begin{tabular}{|c|c|c|}
\hline 밈ㅁㅁ & $\begin{array}{l}\text { Revista Electrónic } \\
\text { Educación y Cultura en }\end{array}$ & $\begin{array}{l}\text { Educación. } \\
\text { la Información. }\end{array}$ \\
\hline & http://www.usal.es/teoriaeducacion & Vol. 10. No 1. Marzo 2009 \\
\hline
\end{tabular}

\subsection{HeRoSaPrI.}

HeRoSaPrI empezó la actividad y discusión en el debate. Sin embargo, los acuerdos iniciales recogieron una planificación de reuniones síncronas como complemento a este espacio. Estas reuniones devinieron "imprescindibles para definir líneas a seguir durante la semana, poder debatir diferentes puntos de vista y analizar el trabajo hecho con un espíritu de autocrítica constructiva”. En algunas ocasiones el Chat se utilizó también como un apoyo en situaciones de conflicto o duda. Un ejemplo de esta situación es el siguiente mensaje recogido en el debate: "Estoy acabando el glosario y cuando acabe tengo que generar la paginación que no sé cómo hacerla. Si alguien se pone en el MSN os lo agradeceré”.

Si bien el uso del wiki no quedó recogido en los acuerdos iniciales, empezaron a utilizarlo casi desde el principio a partir de lo acordado en las reuniones síncronas y lo tratado en el debate. Como comentan HeRoSaPrI en la valoración final de su dinámica grupal, "el wiki para nosotros ha sido una herramienta fundamental, tanto a nivel organizativo como incluso comunicativo (...). En general, nos ha resultado muy útil”. Efectivamente, el aspecto del wiki, que facilitaba una versión visual de los diferentes documentos que iban trabajando, evidencia un uso intensivo de esta herramienta para la construcción y revisión del trabajo. El wiki contenía todo el trabajo realizado en relación a las diferentes PECs así como otros elementos (acuerdos iniciales, una imagen con el nombre del grupo, etc.). Este grupo concentró la mayor parte de su actividad en esta herramienta, como puede apreciarse en los acuerdos recogidos en un acta de una de las reuniones síncronas:

- Los materiales recogidos se irán añadiendo en el wiki para que pueda ser consultado por el resto de miembros del grupo.

- En el wiki se añadirá una página para poner ejemplos de mashups significativos que se vayan encontrando y otra para recursos bibliográficos.

- El wiki se adaptará para darle la misma estructura que las PECs.

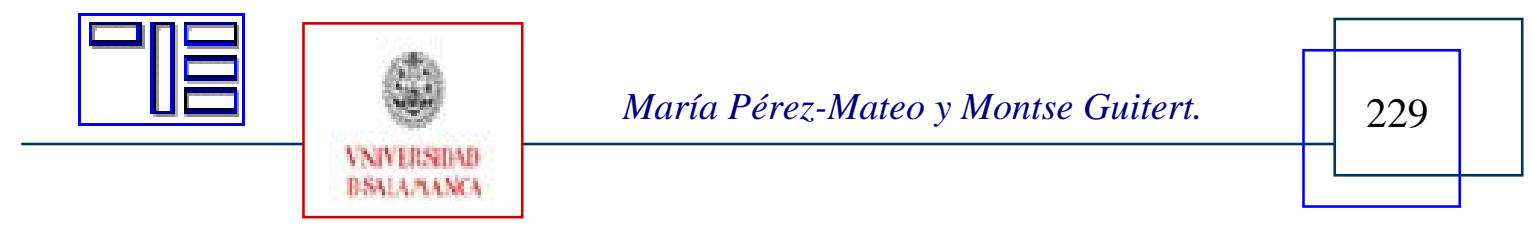




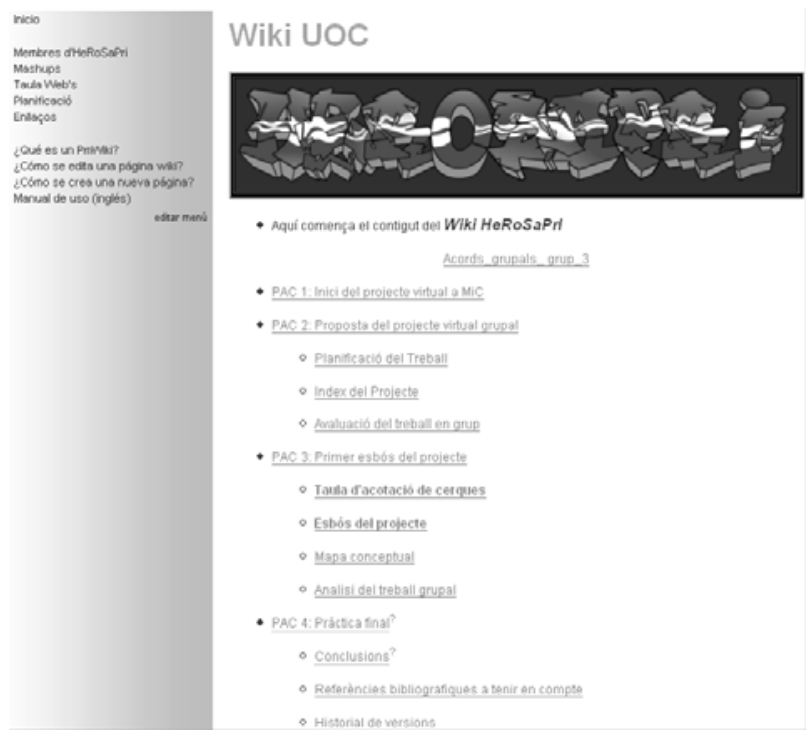

Fig. 7. Wiki HeRoSaPrI.

HeRoSaPrI utilizó el área de ficheros como complemento a la actividad realizada en las reuniones síncronas, el wiki y el debate. Este grupo organizó el área de ficheros siguiendo el esquema que proponía uno de los miembros en el espacio del grupo "He creado algunas carpetas personales donde cada uno puede poner las aportaciones que tenga que hacer según la parte del trabajo que haga, no sé qué os parece? También una carpeta con el nombre Mashups donde querría que colgásemos todo lo que nos encontremos en la web sobre el tema... os parece bien?” A raíz del trabajo realizado en el grupo, fueron añadiendo otras como los acuerdos iniciales, las reuniones (síncronas, en las que guardaban las actas, logs y orden del día) y el wiki, que contenía únicamente la imagen

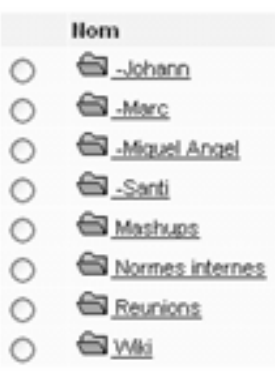

Vol. Total: $93 \mathrm{Nh}$ con el nombre del grupo que había en el wiki.

Fig. 8. Área de ficheros.

A excepción de la carpeta destinada al proyecto final que no fue construido en el wiki, las otras carpetas no contienen versionados de documentos, sino archivos complementarios para su creación y el archivo final recogido a partir de la actividad del wiki. El área de ficheros recoge todos los archivos tratados en el wiki.

Por último, este grupo utilizó el debate como eje organizador o de gestión de estas tres herramientas. Los siguientes mensajes del debate y evidencian su complementariedad y la función comunicativa del debate.

"Por cierto!!! Se ha de modificar el enlace en el wiki y hacer la tabla del casasvacías!!!”

"Disponible el mapa conceptual de los Mashups en el wiki y en el área de ficheros carpeta/Wiki/ppt o Jpg.”

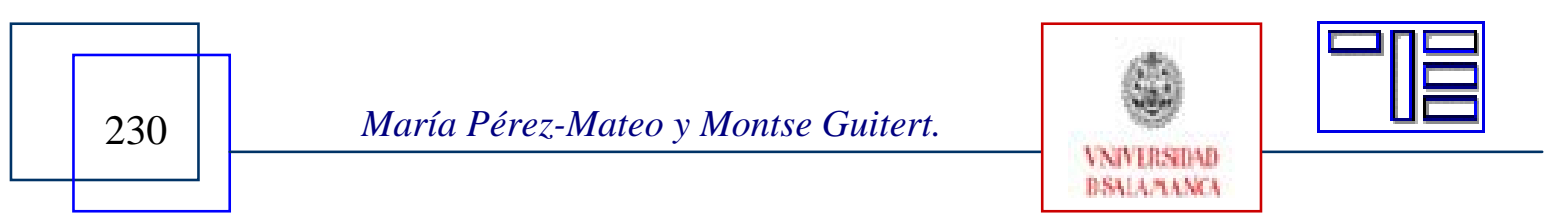




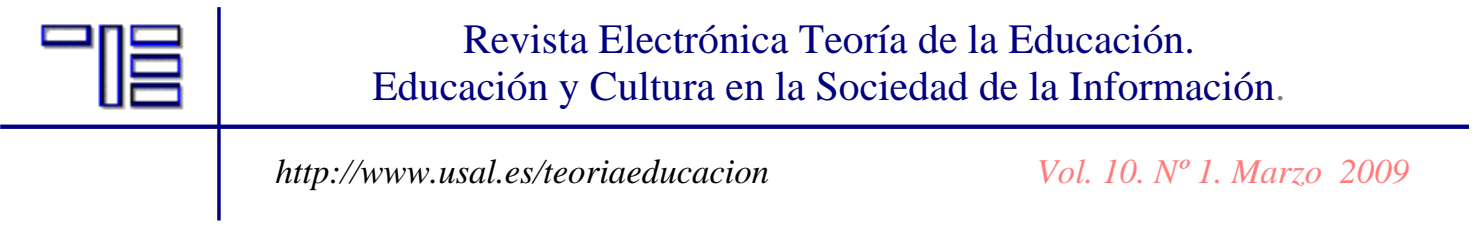

"Encontrareis en el wiki la tabla de búsquedas preparada para introducir todos los enlaces del apartado que tenéis asignado. De cara al domingo [reunión síncrona] tendría que estar completa".

"Convocatoria de reunión HeRoSaPri 25/11/2007. Trataremos los temas publicados en la convocatoria/área de ficheros."

En esta línea, los temas a tratar en las reuniones y los diferentes avances a partir de lo acordado en éstas, quedaban reflejados en el debate. Por ejemplo:

Santiago: enviaré una pregunta al consultor sobre la duda que ha planteado Marc. Johann: ok. Cualquier cosa deja un post en el debate.

HeRoSaPrI realizó un uso muy equilibrado de las herramientas para alcanzar los objetivos propuestos. El debate devino la principal herramienta de comunicación del grupo a partir de la cual coordinaban y organizaban el trabajo a realizar. Sin embargo y en comparación a los otros grupos, utilizó poco el debate, puesto que la mayor parte del trabajo se realizó en el wiki y la discusión se llevó a cabo mediante reuniones síncronas. Si bien el grupo disponía de toda la información necesaria en el wiki, el grupo acordó ya desde el inicio guardar una copia de todos los documentos creados en el área de ficheros para tener un repositorio del trabajo realizado en el caso de haber algún problema con el wiki.

\section{5.- DISCUSIÓN DE RESULTADOS.}

El análisis realizado evidencia que los grupos adaptan las diferentes herramientas, configurando dinámicas que presentan similitudes y diferencias en el uso de los espacios y el tipo de comunicación en relación a los aspectos sociales. A partir del análisis descriptivo de los tres grupos escogidos y la triangulación con el cuestionario que recoge las impresiones de todos los estudiantes del aula, se analiza el uso general que los grupos realizaron de las diferentes herramientas destinadas para el trabajo en grupo virtual.

\subsection{Debate.}

El debate es inicialmente la herramienta principal de comunicación de todos los grupos. Este hecho puede deberse a dos razones principales: es el espacio del que tienen más información y experiencia, ya que es la herramienta común que hay en todas las aulas de la UOC y antes de empezar el proceso en grupo realizan un debate moderado por el consultor; y disponen de un documento con orientaciones pedagógicas para realizarlo.

En general, todas las personas que contestaron el cuestionario coincidieron en que este espacio deviene "muy útil", "imprescindible", "indispensable", "esencial”, etc. Un miembro de un grupo afirmó que "sin duda alguna la básica de ellas es el debate, donde se puede hacer todo lo que se hace con las otras herramientas mediante "adjuntar

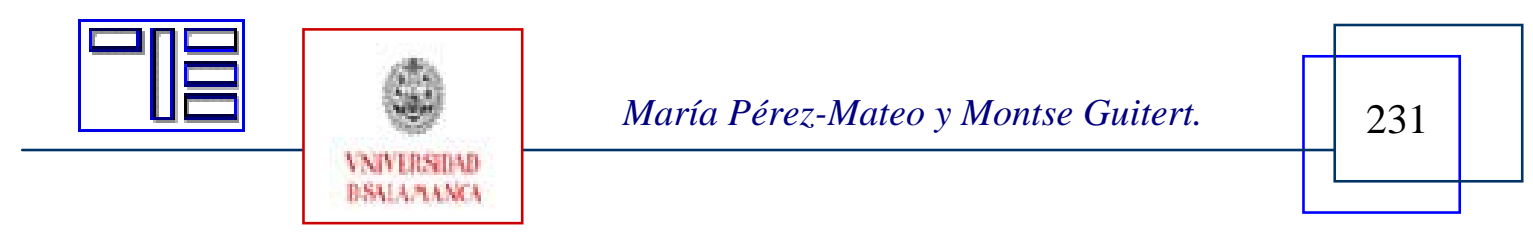


archivos" a los mensajes". Algunos de ellos remarcaban también la importancia del factor asincronía como elemento clave para el éxito de este espacio.

El cuestionario revela que los grupos usan este espacio con 3 finalidades principales: la gestión del proyecto; el intercambio de información y construcción de conocimiento; y la comunicación, vinculada a aspectos sociales o informales.

En primer lugar, la mayor parte de los mensajes de los grupos se destinan a cuestiones de gestión del proyecto. Esto incluye mensajes de organización, toma de decisiones, resolución de problemas o dudas, compartir los mensajes del consultor, etc. Los siguientes son ejemplos del debate de los tres grupos analizados:

“Como dije en el post anterior esto avanza muy rápido. ¿Qué tal si hacemos un repaso de temas pendientes?:

- Desarrollo del punto 2.2 (en principio lo tenía asignado Jorge)

- Estadísticas y gráficos - buen trabajo Ana, aunque en la versión 4 de la BBDD aún no están recogidas las ultimas valoraciones - sólo hay 15 sites.

- Conclusiones - podremos desarrollarlas cuándo dispongamos de un ranking final

- Índices de imágenes y tablas (cuando hayamos finalizado el resto)

-Glosario de términos - Qué os parece si aprovechamos el debate para hacer una pequeña lista de términos que deberían incluirse en este glosario?”

"He bajado la WQ3 para trabajar en ella. Cuando esté la vuelvo a colgar con el nombre WQ4. Tenlo en cuenta, de no hacer modificaciones en paralelo”.

“Hola José Antonio, si no te importa, ¿podrías subir una muestra de los puntos iniciales que estas trabajando y así me puedo hacer una idea de la línea que está siguiendo?”

En segundo lugar, encontramos otra tipología de mensajes relacionados con el intercambio de información, construcción de conocimiento y, en definitiva, la elaboración del trabajo. En estos encontramos mensajes en los que se comparte, intercambia y debate información, ideas, sugerencias u opiniones, a la vez que se informa de nuevos documentos o versiones en el área de ficheros o wiki. El debate, por tanto, fue fundamental para la discusión de los diferentes temas que surgían a partir de la resolución del trabajo y "sobre todo un espacio donde hemos consultado todo sobre nuestro proyecto". Un ejemplo de estos mensajes en el debate de uno de los grupos analizados es el siguiente:

"He anotado una referencia más a las que ya había (v. 1.2), se trata de una referencia bibliográfica al libro la Galaxia Internet del profesor Manuel Castells. Como no se si podréis acceder a él, os envío el texto que creo que podemos relacionar con los riesgos de una Web 2.0 más avanzada, pero también más controlada: (...)”

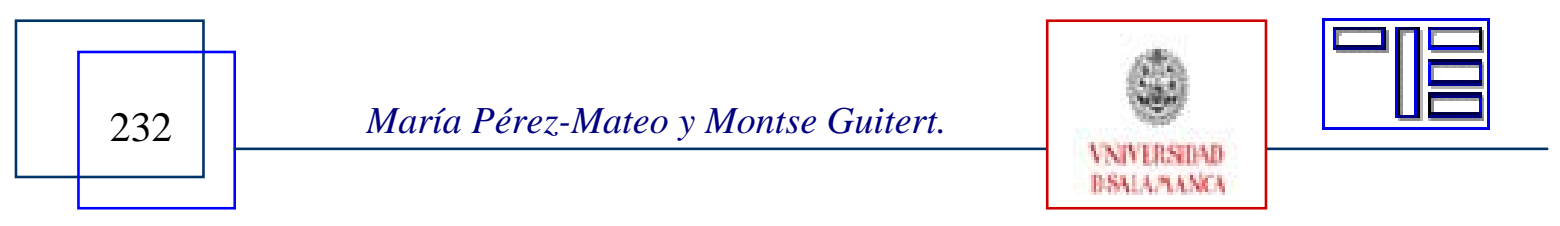


En tercer lugar, los comentarios de los encuestados evidencian el papel comunicativo y social de este espacio. Si bien en la literatura especializada existe cierta diversidad en cuanto a la denominación [2] y definición de los aspectos sociales de la comunicación en ambientes de aprendizaje, en concreto entendemos por dimensión, aspecto o contenido social los mensajes o parte de mensajes no relacionados directamente con el contenido formal del tema o asignatura (Henri, 1992) pero que influyen de alguna manera o vienen determinados por la creación de una “dinámica que va mas allá de la posibilidad de contactar con los otros, comunicarse con el profesor o de recibir feed-back del contenido de un mensaje” (Badia y Mominó, 2001,165).

En esta línea, diferentes personas juzgaron el debate como "esencial para la relación entre los miembros", "fundamental para comunicarnos entre nosotros", "ha sido nuestra principal herramienta de comunicación", "se ha convertido en uno de los ejes de comunicación junto con el área de ficheros", "ha sido el principal punto de encuentro del grupo", quedando reflejada la importancia de este aspecto comunicativo ligado al debate en todos los acuerdos iniciales de los grupos... Por ejemplo, la cantidad de mensajes enviados al debate del grupo Admin2.0. (480), evidencia la importancia de este espacio para la dinámica del grupo. Como decía uno de los miembros en el cuestionario, "El espacio de debate ha sido fundamental para comunicarnos entre nosotros durante toda la duración de la asignatura”. En este espacio encontramos numerosas referencias a los aspectos sociales de la comunicación. Los siguientes son ejemplos de este tipo de mensajes:

"Yo también encuentro que está muy bien Anna. Me gusta el estilo de dos columnas que has hecho. También encuentro interesante poner bastantes imágenes para hacer más ameno el proyecto".

“i i iFELICIDADES A TODOS POR LA NOTA!!! Ha sido un placer trabajar con vosotros, espero que nos encontremos en otra asignatura, sino ya sabéis dónde encontrar$m e ”$.

"A mi tampoco me ha llegado (...) Me lo podéis hacer llegar sin comprimir?”

"Quedas completamente excusado. ¡La salud va por delante de todo! Ánimos y contamos contigo para que nos ayudes a acabar el trabajo. Como digo siempre y ahora más que nunca... ¡Salud!”

Todos los grupos utilizaron el "Asunto" de los hilos de mensajes para avanzar en la comunicación y expresar elementos de la dimensión social. En la figura de la derecha se muestra un ejemplo de cómo uno de los miembros de Admin2.0 aprovecha el hilo de la conversación para felicitar a un compañero por su trabajo.

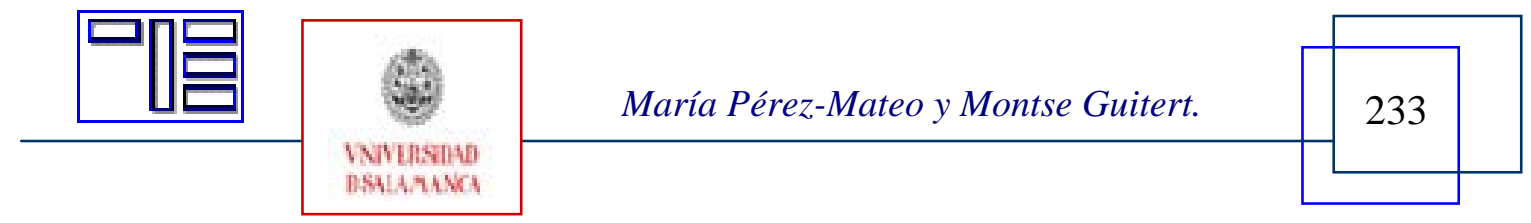


Revista Electrónica Teoría de la Educación.

Educación y Cultura en la Sociedad de la Información.

http://www.usal.es/teoriaeducacion

Vol. 10. No 1. Marzo 2009

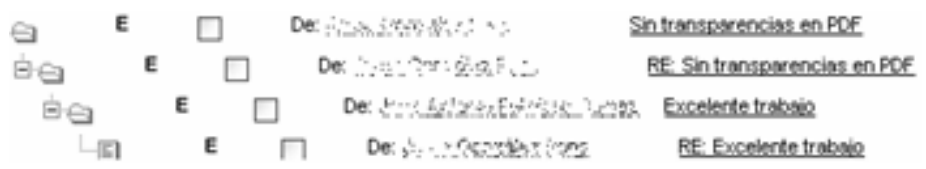

Fig. 9. Hilo de mensajes.

Sin embargo, uno de los miembros de Admin2.0. comentaba que este espacio "en algún caso, se ha convertido en un lío debido al abuso de los posts enviados. Hubiese sido mejor (...) menos posts pero más trabajados". Este comentario concuerda con las investigaciones de Rourke, Anderson, Garrison y Archer (2001) en las que llamaban la atención sobre el peligro de una gran cantidad de presencia social en las conversaciones online en detrimento para el aprendizaje.

Si bien estos elementos de uso del debate son comunes a todos los grupos, la dinámica de cada uno produjo una utilización diferente de esta área, adaptándolo a sus necesidades.

Por ejemplo, Admin2.0 utilizó puntualmente este espacio para realizar reuniones que tenían el objetivo de planificar la semana siguiente. Estas reuniones se realizaron los domingos por la tarde en un periodo de tiempo que oscilaba entre la hora y media y las tres horas. Si bien ésta no es la función principal del debate que apuesta por la asincronía, el grupo escogió esta opción frente al Chat porque como explicaba uno de los miembros "He tenido alguna experiencia en trabajos virtuales cuando estaba en Toulouse y las "horas fijas" de conexión suelen provocar que después no se cumplan bien". De esta manera y en la línea de la UOC desde la que se les anima a trabajar de manera asíncrona, aseguraron el poder trabajar conjuntamente sin depender expresamente del factor tiempo y mantener organizada y visible para todos la información y proceso seguido. La figura muestra una de estas reuniones.
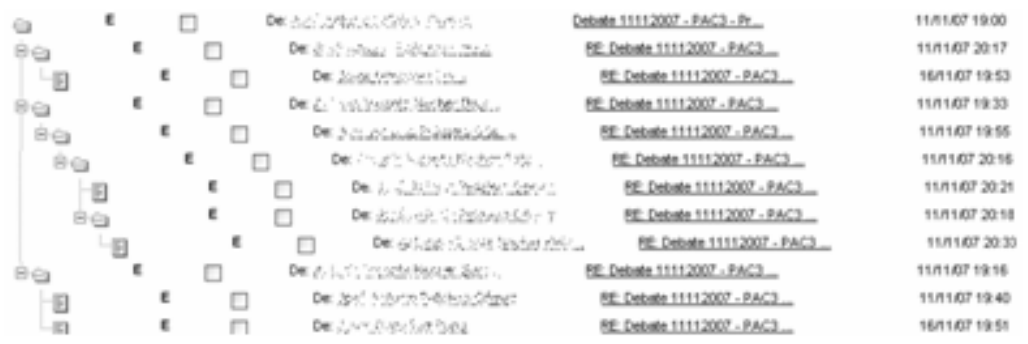

Fig. 10. Coordinación de reunión.

En la misma línea de reuniones, HeRoSaPrI utilizó también este espacio para organizar las reuniones síncronas y aclarar el orden del día:

“Mi mail es ...@hotmail.com. Decidme el vuestro para poneros en el Messenger. ¿A qué hora quedamos para la reunión del domingo? ¿A las 13:30 os va bien o es demasiado tarde?"

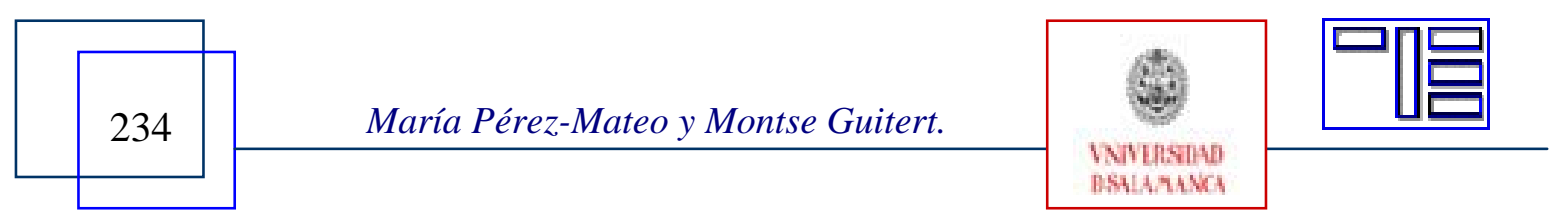


Las distintas dinámicas de los grupos configuraron debates muy diferentes. Por ejemplo, mientras que el grupo Admin2.0 realizó hilos de conversación complejos debido a las reuniones asíncronas, HeRoSaPrI utilizó los hilos de mensajes de una manera más simple, evidenciando que la mayor parte de la discusión del grupo no se llevaba a cabo en este espacio.

No obstante, cabe remarcar que las valoraciones de los grupos evidencian que en todos los casos se ha dado una complementariedad con las otras herramientas utilizadas. Los siguientes mensajes del debate evidencian este hecho:

“Creo que todavía falta definir un poco más la evolución del grupo. Yo en el wiki ya añadí un poco más de cosas. Si pudieseis acabar de escribir más cosas y presentar el documento perfecto".

“He colgado una primera propuesta de planificación... aunque todavía sin distribuir tareas, a la espera de la respuesta del consultor sobre el correo que le he enviado (con copia a vosotros). La podéis consultar tanto en el wiki en formato Excel como en mi carpeta del área de ficheros en formato pdf”.

\subsection{Chat.}

La UOC, como universidad basada íntegramente en Internet, fomenta la comunicación asíncrona para asegurar la flexibilidad y la adaptación a las necesidades específicas de cada estudiante. Sin embargo y teniendo en cuenta que los estudiantes de los grupos suelen demandar una herramienta síncrona de comunicación, se ofreció a la grupos, de manera excepcional, la posibilidad de utilizar el Chat en el seno de los equipos.

El Chat suele ser una herramienta que los grupos utilizan para llegar a acuerdos y tomar decisiones. En este caso concreto, sólo el grupo HeRoSaPrI utilizó esta herramienta. Siguiendo los acuerdos iniciales de este grupo, realizaron un total de 8 reuniones, previstas para los domingos y a partir de diferentes herramientas: el Chat de la UOC; el Messenger y el Skype. En general, estas reuniones devinieron "imprescindibles para definir las líneas a seguir durante la semana, poder debatir diferentes puntos de vista y analizar el trabajo realizado con un espíritu de autocrítica constructiva". También se utilizaron para tomar decisiones, organizarse, resolver dudas, resumir las tareas pendientes, las ya realizadas, etc. El siguiente es un ejemplo en esta línea:

\section{Marc dice:}

respecto al tema de plagio..

Marc dice:

no tengo claro exactamente a qué se refiere... pq fff... a ver, yo leo artículos, y cojo ideas, o se me ocurren ideas propias y me las apunto en un papel y dp redacto

Marc dice:

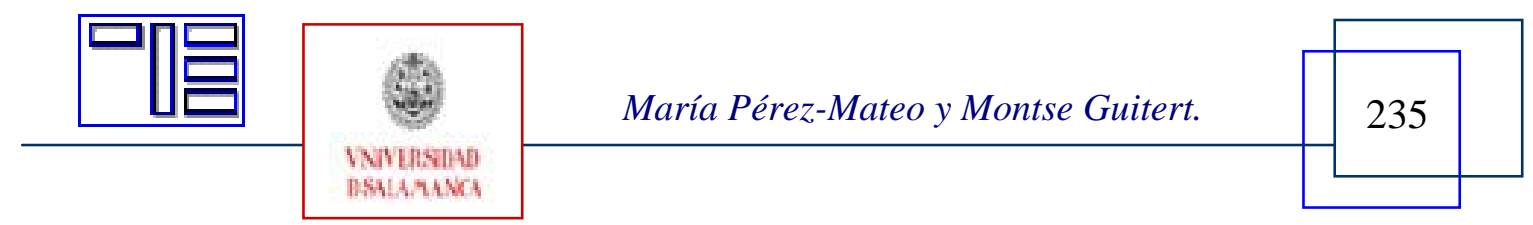


entonces, estoy haciendo plagio?

Santi dice:

nop

Santi dice:

el plagio es que no sea todo un cut\&paste

Santi dice:

se puede hacer, pero cuando lo haces poner la fuente de donde lo has sacado

Marc dice:

vale, pero cómo sé cuándo he de poner alguna referencia?

Seguidamente, uno de los miembros explica cómo y cuándo realiza, en su caso, las citas de los documentos. A partir de aquí, llegan al siguiente acuerdo:

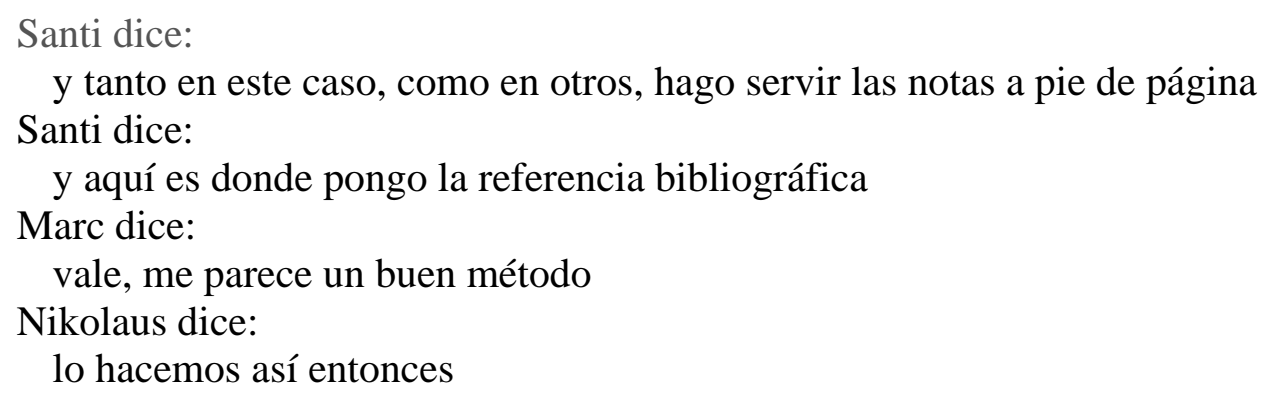

Como muestra este ejemplo, el tipo de comunicación que llevaron a cabo en el Chat fue muy directa, espontánea, dinámica y en algunas ocasiones utilizaban una comunicación habitual en estos espacios: abreviaturas, sin tildes, etc. En estas conversaciones se hicieron servir constantemente elementos de la dimensión social. En primer lugar, el Chat marca una primera parte de interacción social en la que esperan a que todos los compañeros entren a la sala y, mientras tanto, suelen entablar conversaciones informales no relacionadas con el contenido formal del tema. El inicio de todas las reuniones de este grupo evidencia este hecho. En segundo lugar, se observan muchos mensajes de motivación, ánimos, felicitaciones, etc. Por ejemplo, dos miembros comentaban:

\section{Marc dice: \\ ei, somos un grupo genial, eh? \\ Nikolaus dice: \\ jejej somos unos crackkks}

En tercer lugar, se utilizan muchos emoticones y otras expresiones para referirse a la expresión no verbal, usando signos ortográficos, alargamientos de letras, mayúsculas, etc.

Por último, encontramos también numerosos guiños irónicos y notas de humor.

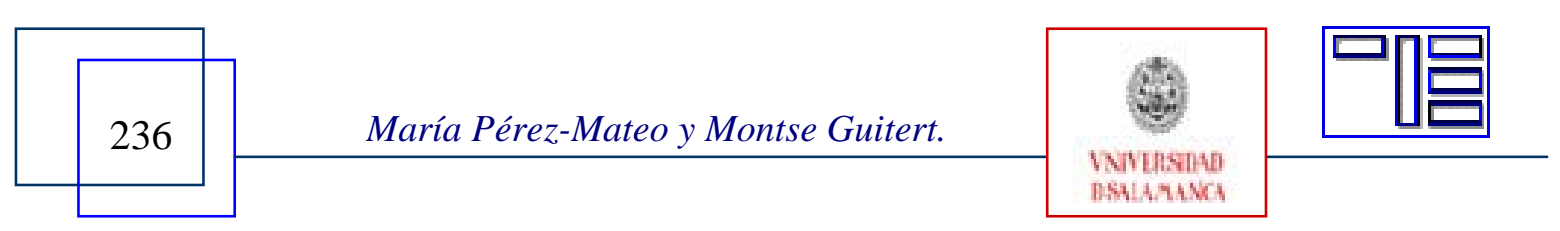




\begin{tabular}{|c|c|c|}
\hline \multirow{2}{*}{ 밈 } & \multicolumn{2}{|c|}{$\begin{array}{l}\text { Revista Electrónica Teoría de la Educación. } \\
\text { Educación y Cultura en la Sociedad de la Información. }\end{array}$} \\
\hline & http://www.usal.es/teoriaeducacion & Vol. 10. No 1. Marzo 2009 \\
\hline
\end{tabular}

\section{3. Área de ficheros.}

El área de ficheros fue utilizada básicamente como un repositorio para favorecer la gestión de la información digital compartida. Si bien desde la asignatura se dan orientaciones para tomar decisiones respecto a la organización de la información, cada grupo organiza esta área en relación al proceso concreto del grupo y los acuerdos iniciales tomados. Las diferentes imágenes del área de archivos de los tres grupos escogidos evidencian este hecho.

Aunque en muchas ocasiones los estudiantes comentan la deficiencia de esta herramienta desde el punto de vista tecnológico, el cuestionario revela que el área de ficheros resultó una herramienta útil para:

\footnotetext{
$\checkmark$ Compartir e intercambiar archivos

$\checkmark$ Subir versiones de los documentos (documentos en proceso)

$\checkmark$ Colgar los trabajos y las partes realizadas por cada persona

$\checkmark$ Avanzar en el desarrollo del trabajo.
}

Sin embargo, no todas las personas que respondieron al cuestionario están de acuerdo en su utilidad. Por ejemplo mientras que uno afirmaba que el área de ficheros "ha resultado bastante útil para colgar todos los ficheros que hacíamos cada uno de nosotros y nos ha permitido ponerlos en común con el resto del grupo. De este modo hemos podido saber como evolucionaba el trabajo de los demás integrantes”, un miembro de otro grupo afirmaba que esta herramienta es "muy útil para documentos definitivos pero no tanto para documentos en creación. No es fácil mover archivos de una carpeta a otra. No permite que los miembros hagan modificaciones y estas queden registradas (control de cambios)".

En todo caso, esta herramienta exigía la complementariedad con otra herramienta en la cual poder llevar a cabo los procesos de comunicación. En esta línea, uno de los encuestados afirmaba que esta herramienta era "La manera más rápida de enviar información al resto del grupo junto con el correspondiente aviso en el espacio de debate. Es necesaria la existencia de este área de ficheros, si no se tendrían que cruzar demasiado emails [en el debate] con los documentos previos al documento final a presentar".

\subsection{Wiki.}

Como se ha señalado anteriormente, el wiki se introdujo en la asignatura como una nueva herramienta para la construcción conjunta de conocimiento. Las orientaciones de uso fueron escasas y se dirigieron básicamente a explicar a grandes rasgos en qué consistía. En esta línea, el consultor escribía en el tablón de la asignatura "El wiki puede tener diferentes páginas, en función de la temática y las tareas a realizar. Por ejemplo, una página donde pongáis las búsquedas que habéis hecho, otra donde vayáis definiendo el

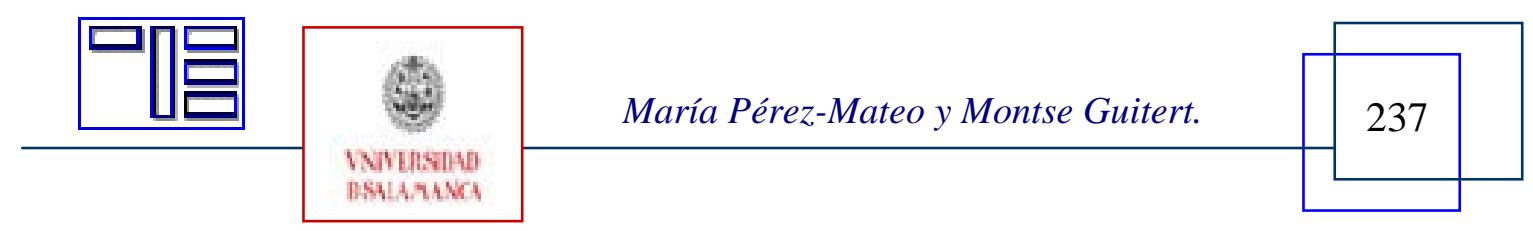


índice, una página inicial, etc.”. Su uso fue voluntario y devino la herramienta que presentó mayor variedad de utilización. Si bien muchos grupos reconocen que usaron el wiki "por debajo de sus posibilidades", otros lo encontraron "muy útil” o "fundamental para el desarrollo del trabajo".

El análisis de los grupos y la triangulación con los datos recogidos en el cuestionario evidencian que los usos que se han realizado del wiki son básicamente tres: como repositorio de archivos compartidos; como herramienta de publicación; y como medio para la construcción del trabajo.

En primer lugar, algunos grupos lo han utilizado de manera similar al área de ficheros, es decir, para el almacenamiento de información. En este sentido, uno de los encuestados afirmaba que habían usado el wiki "más como un repositorio del trabajo hecho que para construir el trabajo”. Admin2.0 devino un ejemplo de esta función.

En segundo lugar, otros grupos lo han considerado útil como herramienta de publicación o autopublicación. Un ejemplo claro de esta función lo hemos encontrado en el grupo Admin2.0. Efectivamente, Admin2.0. publicó "cada una de las fases del estudio, convirtiendo el Wiki en una presentación web de nuestro trabajo". En este sentido, uno de los miembros comenta que el wiki "ha sido muy interesante como herramienta de autopublicación". Esta herramienta devino "fundamental para ir completando el trabajo poco a poco y tener un visión rápida del trabajo”.

En tercer lugar, otros grupos orientaron esta herramienta hacia la construcción del trabajo en el marco de los grupos. En este sentido, algunos resaltaban la posibilidad de "tener un esquema del trabajo realizado y el pendiente", la utilidad para "llegar a acuerdos (con lluvia de ideas por ejemplo)", "desarrollar un documento común”, "fundamental para ir completando el trabajo poco a poco y tener un visión rápida del trabajo", "compartir la información de manera inmediata" y la facilidad para poner "información y entre nosotros lo corregíamos en esta misma herramienta”. En este caso, Edu2.0 y HeRoSaPrI representan dos ejemplos distintos de maneras de trabajar con el wiki para la construcción del trabajo.

Por una parte, como habían acordado en la planificación inicial, el grupo Edu2.0 utilizó el wiki "como herramienta de apoyo a nuestro trabajo", deviniendo el espacio donde "hemos trabajado con la información propiamente del proyecto". Para este grupo, el wiki resultó una herramienta "muy interesante para llegar a acuerdos (con lluvia de ideas por ejemplo)”. Si bien el historial muestra bastantes versiones de los documentos que encontramos en el wiki, cabe decir que la discusión real es mínima y a veces simplemente deviene una aportación de los puntos de vista de cada participante. Por ejemplo, encontramos discusión en el apartado "Esbozo del trabajo" (se evidencia, por ejemplo, en la siguiente situación del wiki "Yo esto no lo pondría en este apartado, lo pondría en el análisis de los grupos-clase en nuestra práctica”). Sin embargo, este

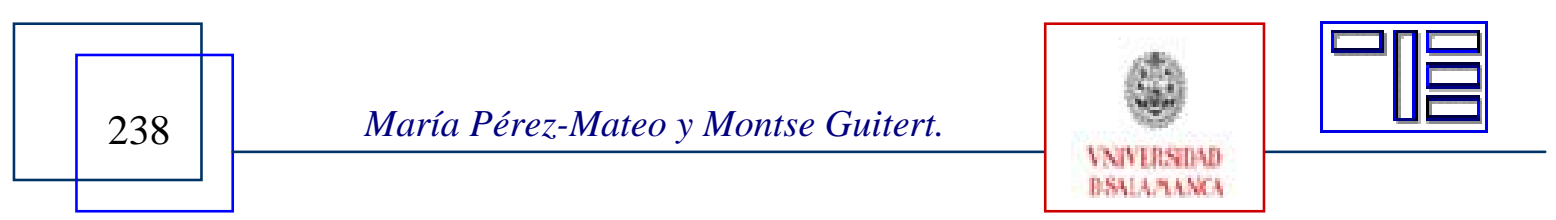


hecho evidencia que este grupo hizo servir el wiki como herramienta de proceso, no disponiendo en este espacio de las versiones finales.

Por otra, HeRoSaPrI utilizó el wiki para seguir el proceso de grupo (a partir de una organización por PEC’s), repartir las tareas, llevar el control de las versiones de documentos a partir de la creación de un historial, etc. HeRoSaPrI, además de construir con esta herramienta el proyecto final, debatía e incluso se encontraron aspectos sociales dentro de esta discusión. Por ejemplo, uno de los miembros pide ayuda en uno de los puntos: “¡Aquí no sé qué poner chicos! A ver si a alguien se lo ocurre alguna cosilla ;-)”. Sin embargo, estos aspectos comunicativos de carácter social los encontramos únicamente al observar el historial de la construcción del wiki, no viéndose en el resultado final de las distintas páginas. El wiki de HeRoSaPrI refleja las versiones finales de los diferentes documentos. Otros aspectos sociales que encontramos en el wiki es la creación de un logo con el nombre del grupo y la localización geográfica de los diferentes miembros, ya que dos de ellos estaban situados en la provincia de Barcelona; otro en Madrid y el último en Helsinki.

El uso que realizaron Edu2.0. y HeRoSaPrI del wiki, evidencia cómo éste devino tanto una herramienta para la adquisición de las competencias especificadas en el Plan Docente de la asignatura, como para la implementación de las mismas.

\section{6.- CONCLUSIONES.}

A partir del análisis realizado se concluye que existe una correlación entre las competencias que los estudiantes ponen en juego a partir del proceso colaborativo desarrollado y las herramientas utilizadas para alcanzar dichas competencias. Sin embargo, éstas no son excluyentes como se puede ver en la siguiente tabla:

\begin{tabular}{||l|l||}
\hline \multicolumn{1}{|c|}{ COMPETENCIAS } & HERRAMIENTAS \\
\hline Gestión de información y documentos & $\begin{array}{l}\text { Área de ficheros } \\
\text { Wiki }\end{array}$ \\
\hline $\begin{array}{l}\text { Elaboración conjunta de la informa- } \\
\text { ción y conocimiento }\end{array}$ & $\begin{array}{l}\text { Wiki } \\
\text { Debate }\end{array}$ \\
\hline Difusión de la información & Wiki \\
\hline Comunicación & $\begin{array}{l}\text { Debate } \\
\text { Chat }\end{array}$ \\
\hline
\end{tabular}

Tabla 2. Relación de competencias y uso de herramientas

De esta manera, cada grupo pone en juego las competencias de trabajo en equipo virtual, pero el proceso mediante el cual las adquieren varía en función de la dinámica del grupo y de las herramientas utilizadas. En todo caso, se observa que estas herramientas son siempre complementarias y existe un equilibrio en su uso. De esta manera, cuando se utiliza el wiki para la construcción del trabajo, se tiende a utilizar el debate para as-

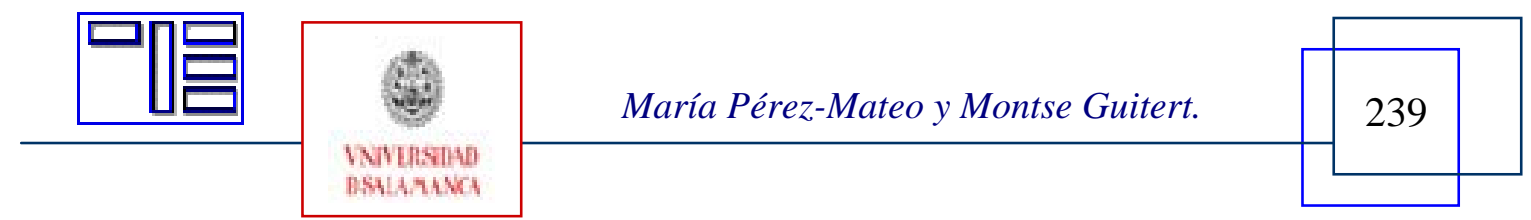


pectos más relacionados con la gestión y organización; por otro lado, cuando la principal herramienta de comunicación y de construcción es el debate, el uso de las otras disminuye o deviene nulo; cuando se introduce el Chat, el debate no se utiliza tanto con una finalidad comunicativa; si el wiki es usado como repositorio, el área de archivos no se utiliza; etc. Esta complementariedad entre las diferentes herramientas se aprecia en la Tabla 1, en la que presentábamos las características específicas de los tres grupos. De ésta se deduce que cuando se utiliza una herramienta con una finalidad, la comunicación, por ejemplo, se utiliza las otras con otras finalidades a la anterior, es decir, para la construcción del trabajo, siguiendo con el ejemplo. En general, los grupos asignan una única finalidad por cada herramienta.

Si focalizamos en el uso del wiki como herramienta de innovación en la asignatura para la adquisición e implementación de las competencias de trabajo colaborativo virtual, el análisis de los grupos de este estudio evidencia que deviene una herramienta adaptable a las necesidades de cada grupo y puede presentar más posibilidades que el debate y el área de ficheros para el almacenamiento de información. En esta línea, el grupo HeRoSaPrI valoraron muy positivamente esta herramienta y afirmaron que "El uso del wiki facilita mucho el trabajo. No hace falta compartir documentos porque es accesible a todos los miembros del grupo. Es fácilmente editable y permite la organización del grupo de una manera diferente y atractiva", permitiendo también "añadir contenidos y modificarlos con un cierto control de quién y cuándo lo ha hecho”.

El análisis realizado conduce a concluir que las maneras de usar las herramientas dependen de tres factores fundamentales:

1. El conocimiento de la herramienta. Muchos de los encuestados reconocían haber utilizado el wiki "por debajo de sus posibilidades reales probablemente porque quizás nos ha faltado un poco de tiempo para continuar trabajándola”. Los estudiantes confirmaban que si habían usado poco el wiki o no lo habían usado se había debido al desconocimiento de esta herramienta y al aprendizaje inicial que requiere. En esta línea, un miembro de un grupo comentaba que "La Wiki parece una buena iniciativa, pero no acabó de cuajar, puede que porque requiere un poco de aprendizaje”. De esto se deduce que en la utilización de una herramienta influye el conocimiento previo y las orientaciones de uso de los docentes.

2. La facilidad de la herramienta, en términos de usabilidad. Las herramientas más fáciles de usar son las más utilizadas. En este aspecto un miembro de un grupo dice que "La curva de aprendizaje inicial del wiki frena su uso como herramienta frente la facilidad del área de debate o el área de ficheros”.

3. Posibilidades tecnológicas. Las posibilidades de las diferentes herramientas marcan también el uso que los grupos realizan con ellas. En este caso, cabe destacar que el Chat y el área de ficheros que suministra la UOC son deficientes desde el punto de vista tecnológico.

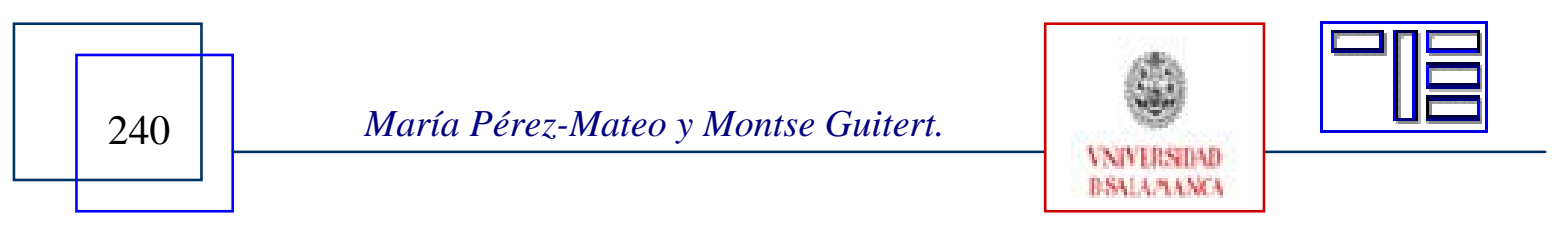


Estos elementos condicionan el uso que realizan los grupos de las diferentes herramientas y determinan, por tanto, las dinámicas que se desarrollan.

Para que puedan explotarse las posibilidades de las herramientas que ofrece la web2.0 para facilitar el aprendizaje colaborativo es necesario el aprendizaje y adaptación a los nuevos recursos para el trabajo en grupo (wikis, blogs, etc.). Introducir el wiki como nueva herramienta para el aprendizaje colaborativo en un aula de MyC ha evidenciado la necesidad de crear una guía que recoja orientaciones de uso y contemplar la dedicación del estudiante para el aprendizaje de la herramienta, aún y teniendo en cuenta que se trata de estudiantes de Ingeniería Informática de los cuales se podría prever un conocimiento sobre estas herramientas.

\section{7.- REFERENCIAS.}

BADIA, A. y MOMINÓ, J. (2001): ¿La interacción es la clave de los procesos de enseñanza y aprendizaje en contextos virtuales instruccionales?, en BARBERÀ, E. (ed.) La incógnita de la educación a distancia. Barcelona, ICE Universitat de Barcelona, Horsori, 157-185.

CONTRERAS-CASTILLO, J.; FAVELA, J.; PÉREZ, C. y SANTAMARÍA, E.M. (2004): Informal interactions and their implications for online courses. Computers and Education, 42 (2), 149-168.

DILLENBOURG, P. (1999): What do you mean by collaborative learning?, en DILLENBOURG, P (ed.) Collaborative-learning: Cognitive and Computational Approaches. Oxford, Elsevier, 1-19.

GUITERT, M. y GIMÉNEZ, F. (2000): El trabajo cooperativo en entornos virtuales de aprendizaje, en DUART, J.M. y SANGRÀ, A. (eds.), Aprender en la virtualidad. Barcelona, Gedisa, 113-134.

GUITERT, M.; ROMEU, T.; PÉREZ-MATEO, M. (2007) Competencias TIC y trabajo en equipo en entornos virtuales. Revista De Universidad y Sociedad Del Conocimiento, 4(1). Ver

http://www.uoc.edu/rusc/4/1/dt/esp/guitert_romeu_perez-mateo.html (Consultado el 13.05.2008)

HARASIM, L.; HILTZ, S. R.; TUROFF, M. y TELES, L. (2000): Redes de aprendizaje. Guía para la enseñanza y el aprendizaje en red. Barcelona, Gedisa.

HENRI, F. (1992): Computer conferencing and content analysis, en KAYE, A. R. (ed.) Collaborative learning through computer conferencing: The Najaden Papers. Berlin, Springer-Verlag, 117-136.

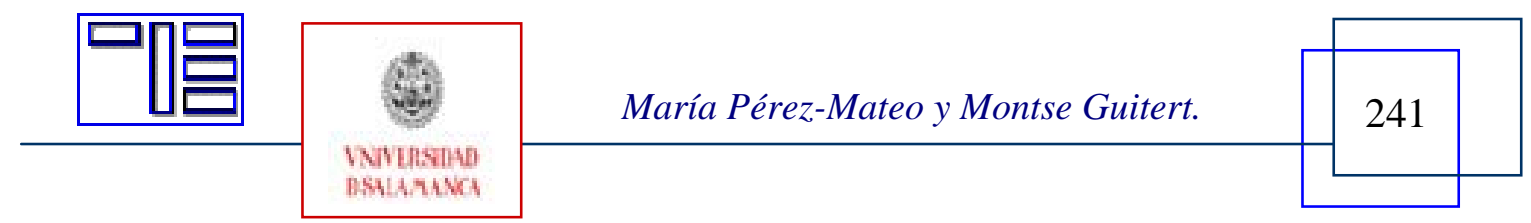


Revista Electrónica Teoría de la Educación.

Educación y Cultura en la Sociedad de la Información.

http://www.usal.es/teoriaeducacion

Vol. 10. No 1. Marzo 2009

MERRIAM, S. B. (1998): Qualitative Research and Case Study Applications in Education. Revised and Expanded from "Case Study Research in Education". San Francisco, Jossey-Bass Inc.

ROURKE, L.; ANDERSON, T.; GARRISON, D. R. y ARCHER, W. (2001): Assessing social presence in asynchronous text-based computer conferencing. Journal of Distance Education, 14 (2), 135-178.

\section{Notas:}

[1] www.uoc.edu

[2] Se pueden encontrar como aspectos sociales o afectivos; aspectos informales o comunicación informal; presencia social; o interacción social, entre otros.

Para citar el presente artículo puede utilizar la siguiente referencia:

PÉREZ-MATEO, María y GUITERT, Montse (2009). Herramientas para el aprendizaje colaborativo en red: el caso de la Universitat Oberta de Catalunya (UOC). En SAN MARTÍN ALONSO, A. (Coord.) Convergencia Tecnológica: la producción de pedagogía high tech [monográfico en línea]. Revista Electrónica Teoría de la Educación: Educación y Cultura en la Sociedad de la Información. Vol. 10, n 1 . Universidad de Salamanca [Fecha de consulta: dd/mm/aaaa].

http://www.usal.es/ teoriaeducacion/rev_numero_10_01/n10_01_perez-

mateo_guitert.pdf

ISSN: 1138-9737
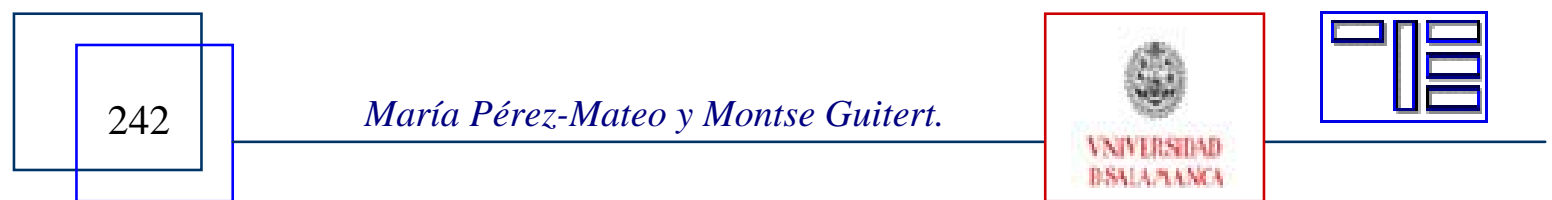